\title{
A Note on Some Solutions of Copper-Water (Cu-Water) Nanofluids in a Channel with Slowly Expanding or Contracting Walls with Heat Transfer
}

\author{
Jawad Raza ${ }^{*}{ }^{\dagger}$, Azizah Mohd Rohni ${ }^{\dagger}$ and Zurni Omar ${ }^{\dagger}$ \\ School of Quantitative Sciences, Universiti Utara Malaysia, Sintok, Kedah 06010, Malaysia; \\ r.azizah@uum.edu.my (A.M.R.); zurni@uum.edu.my (Z.O.) \\ * Correspondence: jawad_6890@yahoo.com; Tel.: +60-111-230-3259 \\ + These authors contributed equally to this work. \\ Academic Editor: Mehmet Pakdemirli \\ Received: 28 March 2016; Accepted: 17 May 2016; Published: 16 June 2016
}

\begin{abstract}
A study has been carried out to examine the occurrence of multiple solutions for Copper-Water nanofluids flows in a porous channel with slowly expanding and contracting walls. The governing equations are first transformed to similarity equations by using similarity transformation. The resulting equations are then solved numerically by using the shooting method. The effects of wall expansion ratio and solid volume fraction on velocity and temperature profile have been studied. Numerical results are presented graphically for the variations of different physical parameters. The study reveals that triple solutions exist only for the case of suction.
\end{abstract}

Keywords: porous channel; triple solutions; expanding and contracting walls

\section{Introduction}

Transport phenomena of the fluid in a channel with contracting or expanding walls have significant applications in the fields of engineering, science and medicine. Blood flows in arteries, vessels, blood flow in artificial kidneys, circulation in the respiratory system and regression of the burning plates in rocket motors are some of the most prominent applications of the flow in a porous channel with expanding or contracting walls [1]. The first attempt to study viscous flow inside a permeable pipe of contracting cross area was by Uchida and Aoki [2]. Later, this problem was illuminated by Bujurke et al. [3] both numerically and analytically. Goto and Uchida [4] presented a theoretical framework of unsteady incompressible laminar flows in a pipe. Suction or injection took place at the walls of pipe and the radius of the pipe as varied with respect to time. In addition, Majdalani et al. [5], Dauenhauer and Majdalani [6], Majdalani and Zhou [7] investigated the problem of laminar flow in a channel with porous expanding walls numerically as well as asymptotically. Later, analytical solutions were obtained by Rahimi et al. [8] for the case of expanding and contracting porous channel walls. Reddy et al. [9] used perturbation techniques to analyze the effects of heat and mass transfer on the asymmetric flow in a porous channel with expanding or contracting walls. A series solution of uniformly expanding or contracting walls in a semi-infinite rectangular porous channel was investigated by Mohyud-din et al. [10]. An analytical solution was investigated by Magalakwe and Khalique [11] regarding the flow and heat transfer between slowly expanding or contracting walls. Xinhui et al. $[12,13]$ analyzed the flow of non-Newtonian fluid in a porous channel with expanding or contracting walls. Many researchers have investigated the fluid flow behavior between expanding or contracting walls analytically as well as numerically under the various fluid flow conditions [14-20].

On the other hand, the most promising implication of nanofluids is the enhancement of heat transfer in modern engineering systems [21-24]. Nanofluids are prepared for increasing 
thermophysical properties, for instance, thermal conductivity, thermal diffusivity, thickness, and convective heat transfer coefficients that have been diverged from those of the base fluids like water, ethylene or tri-ethylene-glucose and diverse coolants, biofluids, and polymer game plans, as clarified by Choi [25] and Wong and Leon [26]. An extensive range of review papers of the nanofluids have appeared in recent years. Freidoonimehr et al. [27] investigated the problem of two dimensional nanofluid flow through expanding or contracting porous walls numerically. None of the investigations cited above did not deal with the multiple solutions of nanofluids in a porous channel. Flow of Carbon nanotubes water-based nanofluid in a channel with expanding or contracting walls was considered by Ahmed et al. [28]. Numerical solutions were obtained by two different numerical schemes called Galerkin's method and Runge-Kutta-Fehlberg method. Hatami et al. [29] discussed the numerical solution of nanofluid flow in a rectangular channel with expanding or contracting porous walls. They concluded that velocity boundary layer thickness near the channel walls decreases as Reynold number and nanoparticles volume fraction increases. Investigations of the authors cited above are confined to the single solution only.

The focus of the present work is to investigate the occurrence of multiple solutions of Copper-water (Cu-water) nanofluid in slowly expanding or contracting walls which has not been studied before. It is hoped that this study will contribute to a better understanding of the flow behavior related to nanofluids in deformable walls.

\section{Problem Formulation}

We consider a two dimensional flow of unsteady, laminar and incompressible nanofluids in a porous channel where the channel walls are variant in the direction of $y$-axis and can be expanded or contracted with respect to the time dependent rate $\dot{a}$. Moreover, both of the channel walls are assumed to have the same permeability, and uniform wall suction/injection is imposed at the walls. The fluid is considered symmetric about $y$-axis as shown in Figure 1.

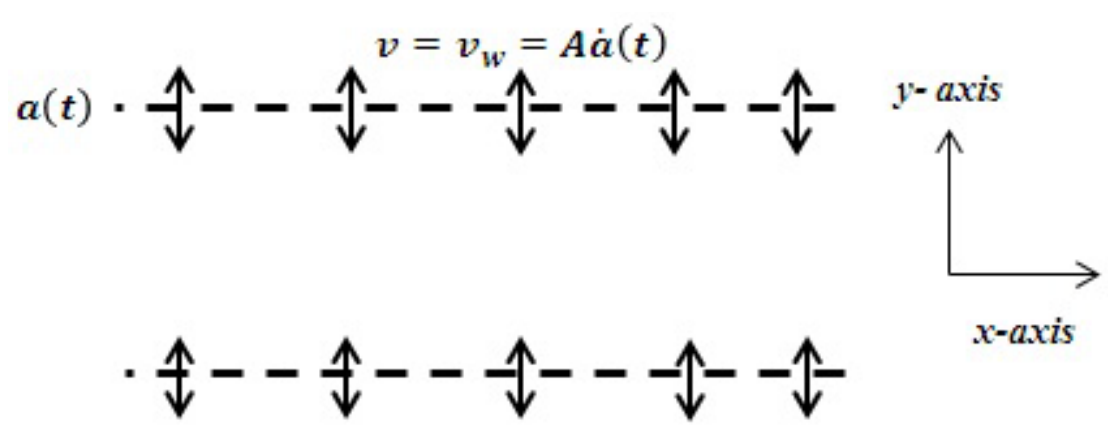

Figure 1. Physical model of the proposed problem.

The governing Equations of the problem is given below:

$$
\begin{gathered}
\frac{\partial \bar{u}}{\partial x}+\frac{\partial \bar{v}}{\partial y}=0 \\
\frac{\partial \bar{u}}{\partial t}+\rho_{n f}\left(\bar{u} \frac{\partial \bar{u}}{\partial x}+\bar{v} \frac{\partial \bar{u}}{\partial y}\right)=-\frac{\partial p}{\partial x}+\mu_{n f}\left(2 \frac{\partial^{2} \bar{u}}{\partial x^{2}}+\frac{\partial^{2} \bar{u}}{\partial y^{2}}+\frac{\partial^{2} \bar{u}}{\partial x \partial y}\right) \\
\frac{\partial \bar{v}}{\partial t}+\rho_{n f}\left(\bar{u} \frac{\partial \bar{v}}{\partial x}+\bar{v} \frac{\partial \bar{v}}{\partial y}\right)=-\frac{\partial p}{\partial y}+\mu_{n f}\left(2 \frac{\partial^{2} \bar{v}}{\partial x^{2}}+\frac{\partial^{2} \bar{v}}{\partial y^{2}}+\frac{\partial^{2} \bar{v}}{\partial x \partial y}\right) \\
u \frac{\partial T}{\partial x}+v \frac{\partial T}{\partial y}=\frac{k_{n f}}{\left(\rho C_{p}\right)_{n f}}\left(\frac{\partial^{2} T}{\partial x^{2}}+\frac{\partial^{2} T}{\partial y^{2}}\right)
\end{gathered}
$$


where $u$ and $v$ are the velocity component along $x$ and $y$ axes respectively, $\rho_{n f}$ is effective density, $\mu_{n f}$ is the effective dynamic viscosity, $\left(\rho C_{p}\right)_{n f}$ is heat capacitance and $k_{n f}$ thermal conductivity of the nanofluid. These physical quantities are described mathematically by Tiwari and Das [30]

$$
\begin{gathered}
\rho_{n f}=\rho_{f}(1-\varphi)+\rho_{s} \\
\mu_{n f}=\frac{\mu_{f}}{(1-\varphi)^{2.5}} \\
\left(\rho C_{p}\right)_{n f}=\left(\rho C_{p}\right)_{f}(1-\varphi)+\left(\rho C_{p}\right)_{s} \varphi \\
\frac{k_{n f}}{k_{f}}=\frac{k_{s}+2 k_{f}-2 \varphi\left(k_{f}-k_{s}\right)}{k_{s}+2 k_{f}+2 \varphi\left(k_{f}-k_{s}\right)}
\end{gathered}
$$

Here $\varphi$ is the solid volume fraction, $\varphi_{s}$ is for nanosolid-particles, $\varphi_{f}$ is for base fluid. Our preference is to solve Equations (1)-(4) through Equations (5)-(9) subject to the boundary conditions

$$
\begin{gathered}
\bar{u}(x, a)=0, \bar{v}(a)=-v_{w}=-A \dot{a}, T=T_{H} \\
\frac{\partial \bar{u}}{\partial y}(x, 0)=0, \bar{v}(0)=0, T=T_{w}
\end{gathered}
$$

Fluid can be injected or sucked with uniform velocity $v_{w}$ at the channel walls. Moreover, the injection/suction coefficient $A \cong \frac{v_{w w}}{\dot{a}}$ that appears in Equation (9) is a measure of wall permeability.

Introduce stream function such that

$$
\bar{u}=\frac{\partial \psi}{\partial y}, \bar{v}=\frac{-\partial \psi}{\partial x}
$$

Solve the system of Equations (1)-(4) and eliminate pressure term from Equations (2) and (3) by introducing vorticity $\omega$, we get

$$
\frac{\partial \omega}{\partial t}+u \frac{\partial \omega}{\partial x}+v \frac{\partial \omega}{\partial y}=\frac{\mu_{n f}}{\rho_{n f}}\left(\frac{\partial^{2} \omega}{\partial x^{2}}+\frac{\partial^{2} \omega}{\partial y^{2}}\right)
$$

where $\omega=\left(\frac{\partial \bar{v}}{\partial x}-\frac{\partial \bar{u}}{\partial y}\right)$.

We can develop similarity solution from the mean flow stream function in the light of boundary conditions Equations (9) and (10). For this, consider $y \equiv \frac{\bar{y}}{a}$ and stream function can be written as:

$$
\psi=\frac{v}{a(t)} \bar{x} \bar{F}(\eta, t) \text { where } \eta=\frac{y}{a(t)}
$$

Put Equation (13) into Equation (11) we get

$$
\bar{u}=\frac{v \bar{x}}{a^{2}(t)} \overline{F_{\eta}}, \bar{v}=\frac{-v}{a(t)} \bar{F}(\eta, t), \theta(\eta)=\frac{T-T_{H}}{T_{w}-T_{H}}
$$

$\overline{F_{\eta}}$ is partial derivative of $\bar{F}$ with respect to $\eta$. Use Equation (14) in Equation (12) we get

$$
(\bar{F})_{\eta \eta \eta \eta}+\frac{v_{f}}{v_{n f}}\left(\alpha\left[\eta(\bar{F})_{\eta \eta \eta}+3(\bar{F})_{\eta \eta}\right]+\bar{F}(\bar{F})_{\eta \eta \eta}-(\bar{F})_{\eta}(\bar{F})_{\eta \eta}\right)-\frac{a^{2}}{v}(\bar{F})_{\eta \eta t}=0
$$

where $\alpha=\frac{\dot{a} a}{v}$ is the wall expansion ratio. 
Subject to boundary conditions

$$
\begin{aligned}
& \overline{F_{\eta}}=0, \bar{F}=R, \theta=0, \eta=1 \\
& \overline{F_{\eta \eta}}=0, \bar{F}=0, \theta=1, \eta=0
\end{aligned}
$$

Here $R=\frac{a v_{w}}{v}$ is the cross flow Reynolds number and $R>0$ is for injection and $R<0$ for suction through the walls $[8,28,29]$.

For self-similar solution, we consider $f=\frac{\bar{F}}{R}$ by the transformation introduced by Uchida and Aoki [2], Dauenhauer and Majdalani [6]. This can lead us to consider the case $\alpha$ is a constant and $f=f(\eta)$. Therefore, $f_{\eta \eta t}=0$. So Equation (15) becomes:

$$
\begin{gathered}
f^{\prime \prime \prime \prime}+A_{1}(1-\varphi)^{2.5}\left(\alpha\left[\eta f^{\prime \prime \prime}+3 f^{\prime \prime}\right]+R\left(f f^{\prime \prime \prime}-f^{\prime} f^{\prime \prime}\right)\right)=0 \\
\theta^{\prime \prime}+\frac{A_{1}}{A_{2}}(\operatorname{Prf} R+\alpha \eta \operatorname{Pr}) \theta^{\prime}=0
\end{gathered}
$$

Boundary conditions are:

$$
\left.\begin{array}{l}
f(0)=0, f^{\prime \prime}(0)=0, \theta(0)=1 \\
f(1)=1, f^{\prime}(1)=0, \theta(1)=0
\end{array}\right\}
$$

\section{Numerical Computation}

In order to find the numerical solution of Equations (18) and (19) subject to the boundary condition Equation (20) we employ the shooting method. It is important to notice that Equation (18) is fourth order nonlinear ODE so we have to change it into the system of first order ODEs such that:

$$
\begin{gathered}
f^{\prime}=p, p^{\prime}=q, q^{\prime}=s, s^{\prime}=-A_{1}(1-\varphi)^{2.5}(\alpha(\eta s+3 q)+R(f s-p q)) \\
\theta^{\prime}=r, r^{\prime}=\frac{-A_{1}}{A_{2}}(\operatorname{Pr}(\alpha \eta+R f) r)
\end{gathered}
$$

Subject to

$$
\left.\begin{array}{c}
f(1)=1, p(1)=0, \theta(1)=0, q(1)=\alpha_{1}, s(1)=\alpha_{2}, r(1)=\alpha_{3} \\
f^{\prime \prime}(0)=0, f(0)=0, \theta(0)=1
\end{array}\right\}
$$

Here, $\alpha_{1}, \alpha_{2}$ and $\alpha_{3}$ are missing initial conditions. For the shooting strategy it is worth noting that we have to shoot the missing initial conditions presented in Equation (23) such that a solution satisfies the given boundary conditions. The computation of the shooting strategy is done in mathematical software called Maple 18 with the aid of shootlib function. The detail of the said strategy has been described by Meade et al. [31].

\section{Results and Discussions}

This section aims to represent our numerical solutions for the different values of parameters involved. For this we have prepared figures in order to find the multiple solutions for the different values of Reynold number $R$, solid volume fraction $\varphi$ and wall expansion ratio $\alpha$ on skin friction, velocity and temperature profiles.

To have a pervasive understanding of the triple solutions we plot skin friction $f^{\prime \prime}(1)$ against wall expansion or contraction ratio $\alpha$ in Figure 2. From this figure it is observed that skin friction $f^{\prime \prime}(1)$ increases monotonically by the variation of $\alpha \in[-1.0,1.0]$. Physically we can say that variation of $\alpha$ from -1.0 to 1.0 (contracting walls to expanding walls) increases wall drag. This is only because, in the case of expanding walls, $\alpha>0$ flow towards the center become fast due to the space caused by 
wall expansion. Moreover, a slip regime exists near the wall. Therefore, for expanding walls $\alpha>0$ skin friction increases numerically for all the solutions. It is worth highlighting that there exists only single solution in the case of injection $(R>0)$ and triple solutions are exist only for the case of suction $(R<0)$. However, to conserve space, we only include the results for the case of suction $(R<0)$ in this paper.

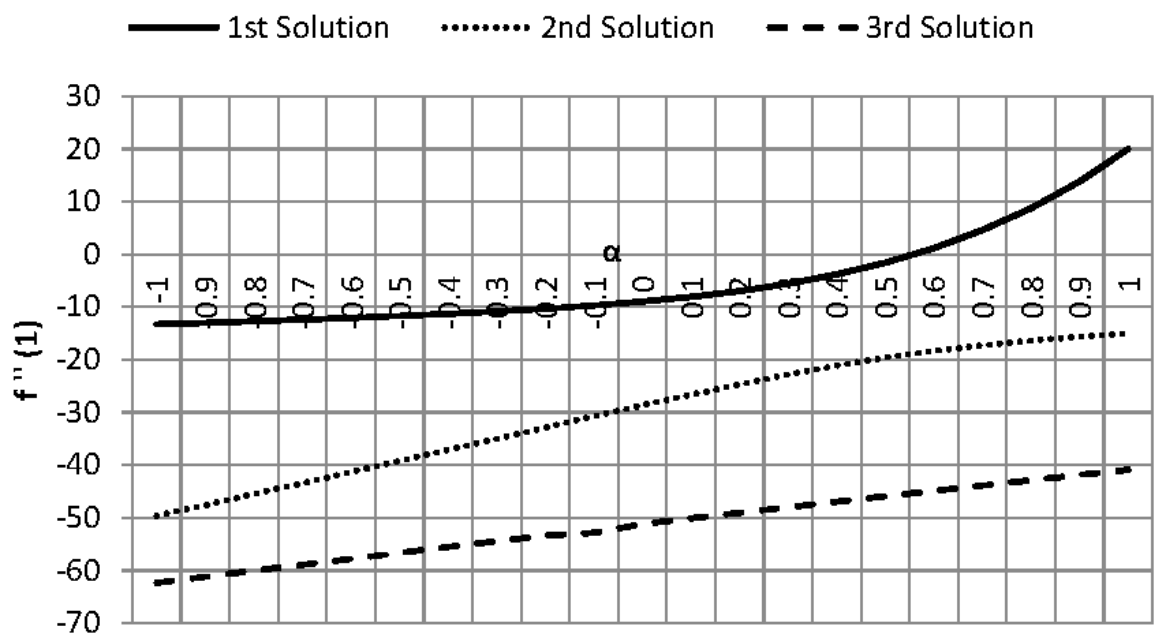

Figure 2. Skin friction $f^{\prime \prime}(1)$ against the variation of $\alpha$ (wall expansion or contraction ratio).

Figure 3 depicted the behavior of velocity profile $f^{\prime}(\eta)$ and temperature profile $\theta(\eta)$ for the variations of solid volume fraction $\varphi$ for the fixed values of Reynold number $R$ and wall expansion ratio $\alpha=0.1$. It is noticed that velocity profile $f^{\prime}(\eta)$ decreases near the center of the channel for the 1st and 3rd solutions. However, the reverse phenomena for the case of 2nd solution is observed. Similarly, the effect of solid volume fraction $\varphi$ on temperature profile $\theta(\eta)$ is presented in the same figure. Temperature profile $\theta(\eta)$ is decreased as the strength of solid volume fraction $\varphi$ increases. Moreover, asymptotical behavior is also observed for the 3rd solution.

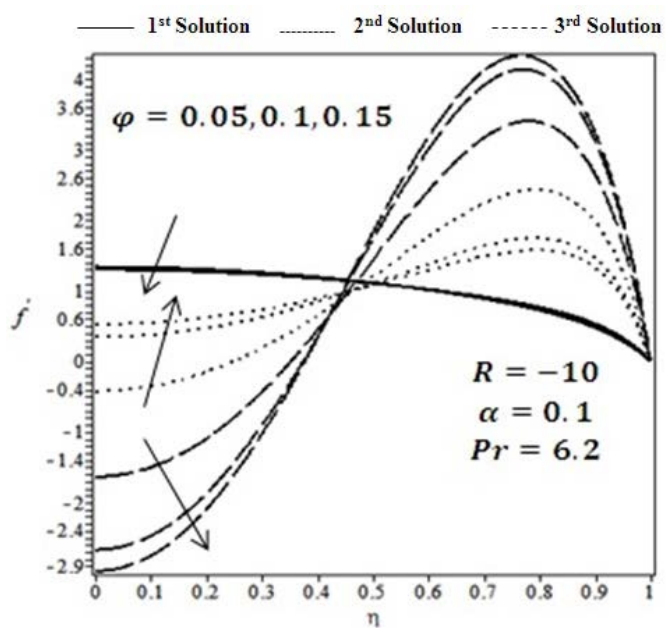

(a)

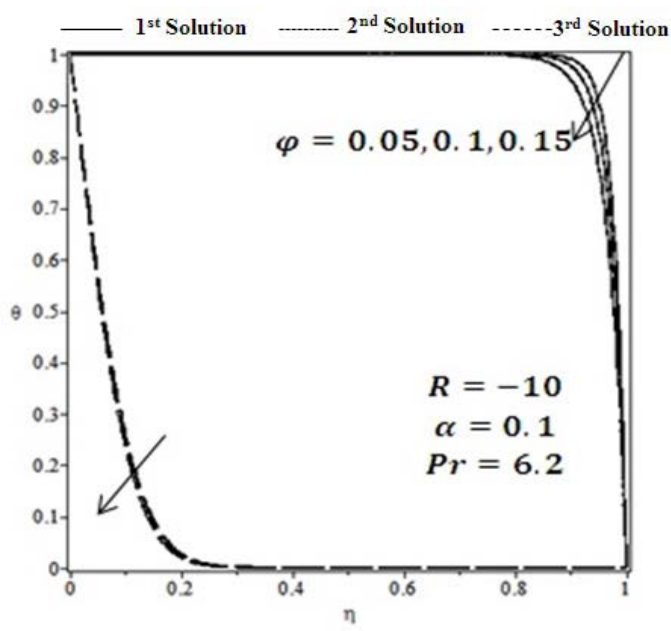

(b)

Figure 3. Effect of Solid Volume Fraction $\varphi$ on (a) Velocity Profile $f^{\prime}(\eta)$ and (b) Temperature Profile $\theta(\eta)$ for Expanding walls.

Figure 4a,b show the effect of solid volume fraction $\varphi$ for the fixed values of Reynold number $R$ and wall expansion ratio $\alpha=-0.1$ on velocity and temperature profiles, respectively. It is observed 
that the trend of fluid velocity and temperature profile are the same as for expanding walls, $\alpha>0$. The effect of wall expansion $\alpha>0$ on velocity $f^{\prime}(\eta)$ and temperature $\theta(\eta)$ is depicted in Figure $5 \mathrm{a}, \mathrm{b}$, respectively. It is seen from Figure 5 that velocity near the center of the channel increases for 1 st and 2nd solutions and decreases for the 3rd solution. However, the opposite happens near the wall. This is because fluid moves freely near the center of the channel due to the space generated by the wall expansion, so therefore fluid velocity $f^{\prime}(\eta)$ increases gradually near the center of the channel $\eta \approx 0$. Furthermore, temperature profile decreases gradually by increasing the values of wall expansion, and asymptotical behavior is observed for the 3rd solution. Figure 6 presented the effect of wall contraction $\alpha<0$ on velocity profile $f^{\prime}(\eta)$ and temperature profile $\theta(\eta)$ for the fixed values of solid volume fraction $\varphi$ for the fixed values of Reynold number $R$. On the other hand, velocity profile $f^{\prime}(\eta)$ decreases near the center of the channel and increases near the channel wall for the case of wall expansion ratio $\alpha<0$ as shown in Figure 6. Contracting walls $\alpha<0$ provide less space for the fluid to flow so therefore fluid velocity near the center of the channel decreases, flow towards the channel wall becomes more noticeable and temperature profile increases for all the solutions.

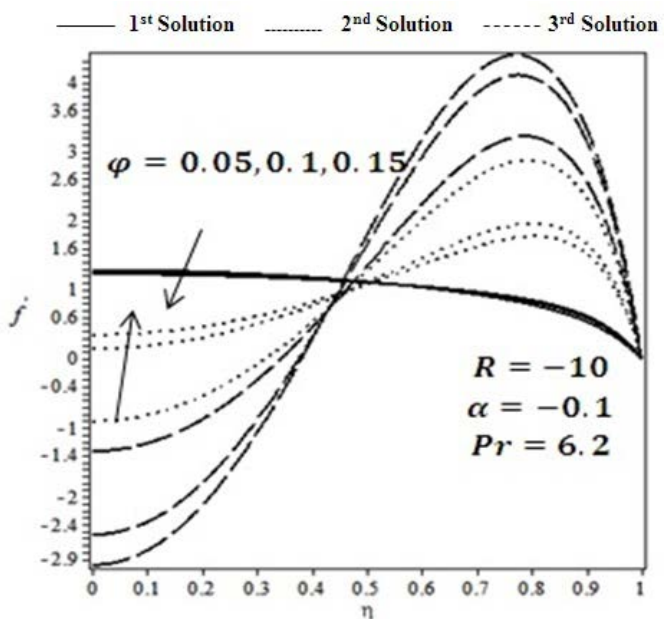

(a)

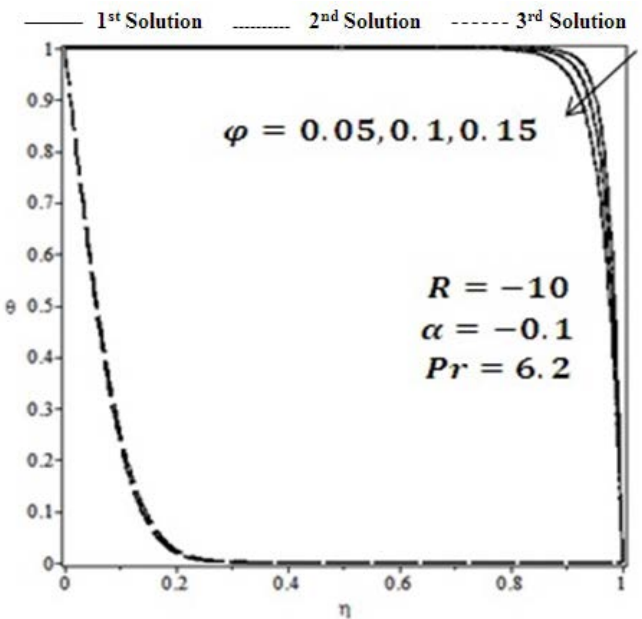

(b)

Figure 4. Effect of Solid Volume Fraction $\varphi$ on (a) Velocity Profile $f^{\prime}(\eta)$ and (b) Temperature Profile $\theta(\eta)$ for Contracting walls.

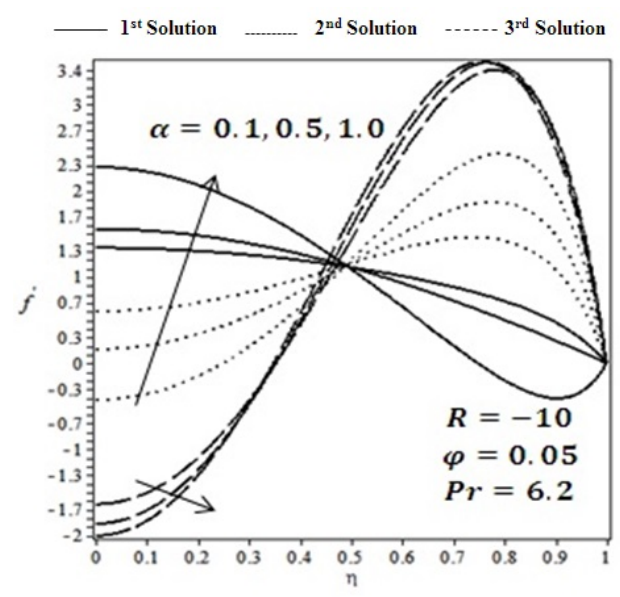

(a)

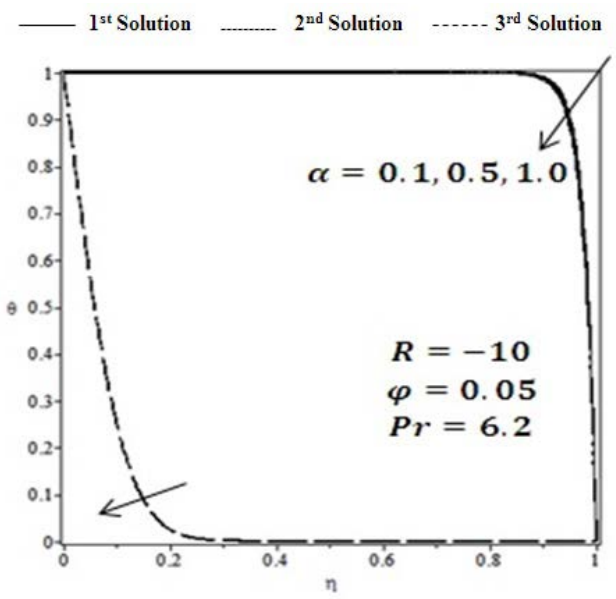

(b)

Figure 5. Effect of Wall expansion $\alpha>0$ on (a) Velocity Profile $f^{\prime}(\eta)$ and (b) Temperature Profile $\theta(\eta)$. 


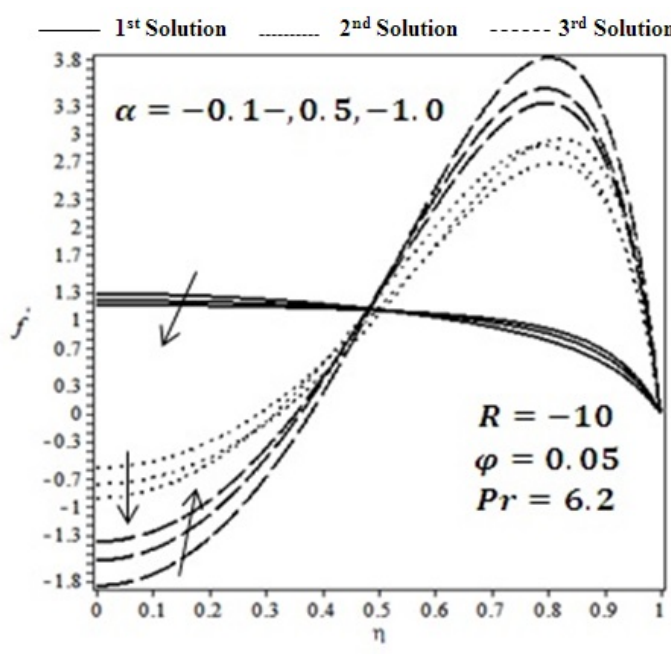

(a)

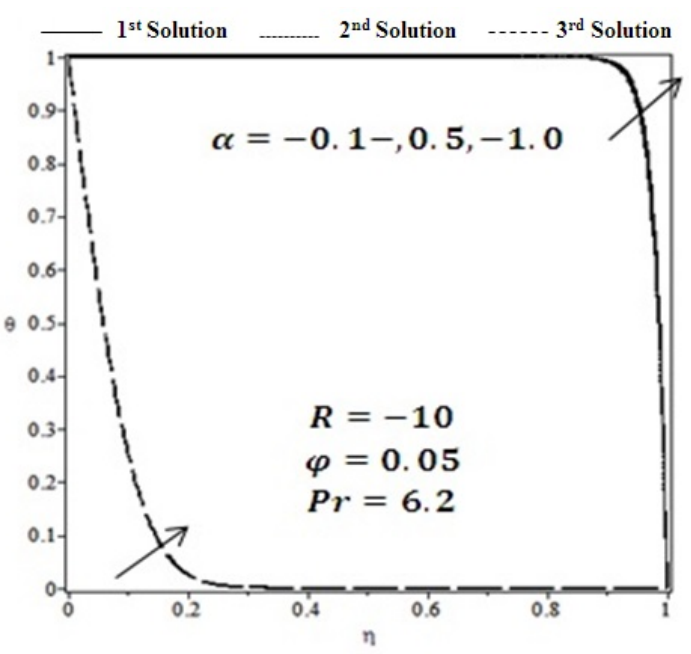

(b)

Figure 6. Effect of Wall contraction $\alpha<0$ on (a) Velocity Profile $f^{\prime}(\eta)$ and (b) Temperature Profile $\theta(\eta)$.

\section{Conclusions}

Two dimensional flow of nanofluid in slowly expanding or contracting walls is studied in this paper. Effects of different physical parameters were analyzed. On the bases of these effects the following conclusions have been made:

1. In the case of injection $R>0$ through porous walls for any value of expanding walls $(\alpha>0)$, contracting walls $(\alpha<0)$ and solid volume fraction $\varphi>0$, there exists only a single solution.

2. Velocity of the nanofluid particles increases at the center of the channel $\eta \approx 0$ as the channel walls expands $\alpha>0$ and decreases as the channel walls contract $\alpha<0$.

3. The effects of solid volume fraction $\varphi$ on the velocity profile $f^{\prime}(\eta)$ and temperature profile $\theta(\eta)$ for both contracting and expanding walls $(\alpha<0$ and $\alpha>0)$ are the same.

Author Contributions: All the authors equally contributed to this work.

Conflicts of Interest: The authors declare no conflict of interest.

\section{References}

1. Chang, H.N.; Ha, J.S.; Park, J.K.; Kim, I.H.; Shin, H.D. Velocity field of pulsatile flow in a porous tube. J. Biomech. 1989, 22, 1257-1262. [CrossRef]

2. Uchida, S.; Aoki, H. Unsteady flows in a semi-infinite contracting or expanding pipe. J. Fluid Mech. 1977, 82, 371-387. [CrossRef]

3. Bujurke, N.M.; Pai, N.P.; Jayaraman, G. Computer extended series solution for unsteady flow in a contracting or expanding pipe. IMA J. Appl. Math. 1998, 60, 151-165. [CrossRef]

4. Goto, M.; Uchida, S. Unsteady flows in a semi-infinite expanding pipe with injection through wall. J. Jpn. Soc. Aeronaut. Space Sci. 1990, 38, 131-138. [CrossRef]

5. Majdalani, J.; Zhou, C.; Dawson, C.A. Two-dimensional viscous flows between slowly expanding or contracting walls with weak permeability. J. Biomech. 2002, 35, 1399-1403. [CrossRef]

6. Dauenhauer, C.E.; Majdalani, J. Exact self-similarity solution of the Navier-Stokes equations for a porous channel with orthogonally moving walls. Phys. Fluids 2003, 15, 1485-1495. [CrossRef]

7. Majdalani, J.; Zhou, C. Moderate-to-large injection and suction driven channel flows with expanding or contracting walls. Z. Angew. Math. Mech. 2003, 83, 181-196. [CrossRef]

8. Rahimi, E.; Rahimifar, A.; Mohammadyari, R.; Rahimipetroudi, I.; Rahimi-Esbo, M. Analytical approach for solving two-dimensional laminar viscous flow between slowly expanding and contracting walls. Ain Shams Eng. J. 2015. [CrossRef] 
9. Subramanyam Reddy, A.; Srinivas, S.; Ramamohan, T.R. Analysis of heat and chemical reaction on an asymmetric laminar flow between slowly expanding or contracting walls. Heat Transf. Asian Res. 2013, 42, 422-443. [CrossRef]

10. Mohyud-Din, S.T.; Yıldırım, A.; Sezer, S.A. Analytical approach to a slowly deforming channel flow with weak permeability. Z. Naturforschung 2010, 65, 1033-1038. [CrossRef]

11. Gabriel, M.; Khalique, C.M. Symmetry methods of flow and heat transfer between slowly expanding or contracting walls. Math. Probl. Eng. 2013, 2013, 137930.

12. Si, X.-H.; Zheng, L.-C.; Zhang, X.-X.; Si, X.-Y.; Li, M. Asymmetric viscoelastic flow through a porous channel with expanding or contracting walls: a model for transport of biological fluids through vessels. Comput. Methods Biomech. Biomed. Eng. 2014, 17, 623-631.

13. Si, X.; Zheng, L.; Lin, P.; Zhang, X.; Zhang, Y. Flow and heat transfer of a micropolar fluid in a porous channel with expanding or contracting walls. Int. J. Heat Mass Transf. 2013, 67, 885-895. [CrossRef]

14. Si, X.-H.; Zheng, L.-C.; Zhang, X.-X.; Chao, Y. Perturbation solution to unsteady flow in a porous channel with expanding or contracting walls in the presence of a transverse magnetic field. Appl. Math. Mech. 2010, 31, 151-158. [CrossRef]

15. Jafaryar, M.; Farkhadnia, F.; Mohammadian, E.; Hosseini, M.; Khazaee, A.M. Analytical investigation of laminar flow through expanding or contracting gaps with porous walls. Propuls. Power Res. 2014, 3, $222-229$. [CrossRef]

16. Si, X.; Zheng, L.; Zhang, X.; Chao, Y. The flow of a micropolar fluid through a porous channel with expanding or contracting walls. Open Phys. 2011, 9, 825-834. [CrossRef]

17. Si, X.-H.; Zheng, L.-C.; Zhang, X.-X.; Chao, Y. Homotopy analysis solutions for the asymmetric laminar flow in a porous channel with expanding or contracting walls. Acta Mech. Sin. 2011, 27, 208-214. [CrossRef]

18. Boutros, Y.Z.; Abd-el-Malek, M.B.; Badran, N.A.; Hassan, H.S. Lie-group method solution for two-dimensional viscous flow between slowly expanding or contracting walls with weak permeability. Appl. Math. Model. 2007, 31, 1092-1108. [CrossRef]

19. Asghar, S.; Mushtaq, M.; Hayat, T. Flow in a slowly deforming channel with weak permeability: An analytical approach. Nonlinear Anal. Real World Appl. 2010, 11, 555-561. [CrossRef]

20. Si, X.-H.; Zheng, L.-C.; Zhang, X.-X.; Si, X.-Y.; Yang, J.-H. Flow of a viscoelastic fluid through a porous channel with expanding or contracting walls. Chin. Phys. Lett. 2011, 28, 044702. [CrossRef]

21. Kleinstreuer, C.; Li, J.; Koo, J. Microfluidics of nano-drug delivery. Int. J. Heat Mass Transf. 2008, 51, 5590-5597. [CrossRef]

22. Shi, P.; He, P.; Teh, T.K.H.; Morsi, Y.S.; Goh, J.C.H. Parametric analysis of shape changes of alginate beads. Powder Technol. 2011, 210, 60-66. [CrossRef]

23. Emerich, D.F.; Thanos, C.G. The pinpoint promise of nanoparticle-based drug delivery and molecular diagnosis. Biomol. Eng. 2006, 23, 171-184. [CrossRef] [PubMed]

24. Bég, O.A.; Prasad, V.R.; Vasu, B. Numerical study of mixed bioconvection in porous media saturated with nanofluid containing oxytactic microorganisms. J. Mech. Med. Biol. 2013, 13, 1350067. [CrossRef]

25. Choi, S.U. Nanofluids: From vision to reality through research. J. Heat Transf. 2009, 131, 033106. [CrossRef]

26. Wong, K.V.; De Leon, O. Applications of nanofluids: Current and future. Adv. Mech. Eng. 2010, 2, 519659. [CrossRef]

27. Freidoonimehr, N.; Rostami, B.; Rashidi, M.M. Predictor homotopy analysis method for nanofluid flow through expanding or contracting gaps with permeable walls. Int. J. Biomath. 2015, 8, 1550050. [CrossRef]

28. Ahmed, N.; Mohyud-Din, S.T.; Hassan, S.M. Flow and heat transfer of nanofluid in an asymmetric channel with expanding and contracting walls suspended by carbon nanotubes: A numerical investigation. Aerosp. Sci. Technol. 2016, 48, 53-60. [CrossRef]

29. Hatami, M.; Sahebi, S.A.R.; Majidian, A.; Sheikholeslami, M.; Jing, D.; Domairry, G. Numerical analysis of nanofluid flow conveying nanoparticles through expanding and contracting gaps between permeable walls. J. Mol. Liq. 2015, 212, 785-791. [CrossRef] 
30. Tiwari, R.K.; Das, M.K. Heat transfer augmentation in a two-sided lid-driven differentially heated square cavity utilizing nanofluids. Int. J. Heat Mass Transf. 2007, 50, 2002-2018. [CrossRef]

31. Meade, D.B.; Haran, B.S.; White, R.E. The shooting technique for the solution of two-point boundary value problems. Maple Tech. Newsl. 1996, 3, 85-93.

(c) 2016 by the authors; licensee MDPI, Basel, Switzerland. This article is an open access article distributed under the terms and conditions of the Creative Commons Attribution (CC-BY) license (http:/ / creativecommons.org/licenses/by/4.0/). 